\title{
Investigation an environmentally friendly method under magnetic field as a green solvent for the synthesis of brookite phase nanoparticles at room temperature
}

Yahya Absalan ( $\sim$ yahyaabsalan2014@gmail.com )

RUDN University https://orcid.org/0000-0003-2738-9645

Mostafa Gholizadeh

Ferdowsi University of Mashhad

Vladimir Viktorovich Kopylov

RUDN: Rossijskij universitet druzby narodov

Leonid Alekseevich Butsov

RUDN: Rossijskij universitet druzby narodov

Olga Kovalchukova

RUDN: Rossijskij universitet druzby narodov

\section{Research Article}

Keywords: TiO2, brookite, magnetized water, nanoparticle, room temperature, green environment

Posted Date: February 22nd, 2021

DOI: https://doi.org/10.21203/rs.3.rs-194179/v1

License: (c) (i) This work is licensed under a Creative Commons Attribution 4.0 International License.

Read Full License

Version of Record: A version of this preprint was published at Journal of Materials Science: Materials in Electronics on April 16th, 2021. See the published version at https://doi.org/10.1007/s10854-021-058894. 


\section{Abstract}

$\mathrm{TiO}_{2}$ nanoparticles in the brookite phase were synthesized within an environmentally friendly method by magnetized water obtained by the US-patent magnetizing device (US10507450B2), which changes the properties of all types of the solvents with no limitation (protic or aprotic). Furthermore, this study is the first report on the synthesis of brookite $\mathrm{TiO}_{2}$ nanoparticle through magnetized water at room temperature. The procedure was tested by five different water; ordinary, 15, 30, 45, and 60min-magnetized water. The products were analyzed by various techniques including XRD, FESEM, ICP, BJH-plot, t-plot, Langmuir plot, BET, TEM, and FTIR. The result showed that the products obtained from 30 min-magnetized water were the most properly indexed $\mathrm{TiO}_{2}$ brookite phase with high surface activity. This sample could be a suitable green photocatalyst.

\section{Introduction}

$\mathrm{TiO}_{2}$ nanoparticle is one of the most proper and popular semiconductors whose applications cover diverse industrial areas including photocatalysis[1,2], thin-film, sunscreen, photovoltaic, electrodes [3,4], sensors $[5,6]$, and drug delivery $[7,8]$. In this regard, $\mathrm{TiO}_{2}$ nanoparticle have been prepared through different methods, including sol-gel [9], inverse micelle [10,11], hydrothermal [12], straight oxidation [1315], chemical vapor deposition [16-18], physical vapor deposition [19-21], electrochemical accumulation [22-24], sonochemical [25], microwave [26-28], and organometallic complex compounds [29-34]. However, almost all of the mentioned methods require high temperature (usually more than 500) [35]. Some of them even need organic solvents which may contaminate the environment. In addition, in the large scale consuming high energy neither environmentally nor economically is affordable. Motivated by the mentioned drawbacks, we tried to find an alternative method to avoid high temperatures and organic solvent in order to have a more clean environment.

Magnetized solvents have been used for more than 50 years in different fields such as chemical reactions [36-44], concrete [45-48], poultry [49,50], oil [51], medicine [49], and agriculture [52]. In all the mentioned areas magnetized solvents, especially water, consumed lower energy; hence they are costeffective and more environmentally friendly.

In all cases, however, a magnetized component is used to magnetize the solvent as the device can't do that. Here, we invented a device to magnetize the solvent; through influencing magnetization, the properties of the solvent can be changed. Moreover, other devices fail to magnetize all the organic and aqueous solvents due to some limitations such as corrosion and combustion, therefore, water is the only solvent for magnetization. Recently, we registered a US-patent magnetizing device [53] (Fig. 1), capable of magnetizing different solvents (with various hydrogen bond angles), with no limitation, through the magnetic field to obtain various properties. The important point is that this device does not magnetize the solvents, but it rather alters their structures and behaviors. By controlling the condition, it is possible to use these new properties in different areas. In our previous work, we reviewed application of magnetized water as green technology, published in journal of cleaner production[54]. Here, in this particular 
experiment, brookite phase nanoparticles were synthesized from an utter environmentally friendly method by means of room temperature and magnetized water using the developed device which worked the same as a centrifuge (Fig. 1). However, the purpose was absolutely different, and it was employed for magnetizing solvent.

\section{The Operation Of The Device (Micro Device)}

The device operates based on the influence of electromagnet rule introduced by Michael Faraday in 1832. After passing through the device, water is affected by the magnetic energy, and hence the physical and electric properties of its colloid particles such as carbonate sodium molecules, salts, and other minerals will be altered. It changes the electrical arrangement of the ions and ultimately prevents sedimentation. Also, the magnetic energy can reduce the surface tension by $10 \%$, making an unfavorable condition for the formation of sticky sediments giving rise to magnetized water. In this experiment, a labscale microdevice was used for the following purposes:

1. Organic reactions are very expensive due to using organic solvents, thus they will not be affordable if high volumes of solvent are employed for magnetizing.

2. Magnetizing high amounts of solvent but just using 5 or $10 \mathrm{cc}$ is energetically not green.

3. Avoiding solvent waste due to applying device with various volumes (Fig.2)

1 - Sample Tube 6- Bearing

2 - Strong Magnets 7- Invertor

3 - U-Shape Groove 8- Rotating Table

4 - Magnetic Field Strength Regulator 9- Screen Protector

5 - Electro Motor

A rotary motor (1500 round per min), frequence ( 50 hertz), and power (1HP) were used to construct this device to raise the fluid speed in the magnetic field to the desired level. By enhancing the particle speed in the magnetic field the influenced magnetic property will be increased.

This device has a plate to hold the fluid sample; the material is PTFE=Poly Tetra Flouro Ethylene which rotates around the axle out of the engine. The device is similar to a centrifuge. They have to work parallelly to make the device balanced, otherwise, the sample container will break due to its collision with holding jaws of the different poles of the magnetic.

Two jaws made of PTFE were responsible for holding a permanent magnet, which is made of neodymium nickel alloy with a dimension of $100 * 50 * 40 \mathrm{~mm}^{3}$ and power of 15000 Gauss. These jaws were ambulant to prepare different intensities of the magnetic field between 2000 and 6500 Gauss. The electromagnetic field can be increased by 20000 Gauss. An electronic part was considered to adjust the 
engine speed. It is one of the most important parameters because by changing the speed of the engine and power of the magnetic field, it is possible to study new subjects on the chemical reaction.

\section{Experiment}

Material. $\mathrm{TiCl}_{3}$ was purchased from the Aldrich with no further purification (>98\%). $\mathrm{NaOH}$ also was purchased with high quality (>99\%) from Aldrich.

Synthesis of $\mathrm{TiO}_{2}$. First of all, $25 \mathrm{ml}$ of deionized water was poured to the glass tube embedded in the device and then closed the door and the round of the engine was set by the invertor (Rotary motor: 1500 round per min, frequence: 30 hertz, and power: $1 \mathrm{HP}$ ), then the device was turned on and the magnetic process was started. For the first sample, the magnetization was set for $15 \mathrm{~min}$ (there are different samples; ordinary as blank, 15 min magnetized, 30 min magnetized, 45 min magnetized, and 60 min magnetized water and the following method was tested for all the obtained water).

$0.15 \mathrm{~mol} / \mathrm{I} \mathrm{TiCl}_{3}(15 \%)$ dissolved in $\mathrm{HCl}$ (10-15\%) was added to $25 \mathrm{ml}$ pre-magnetized water under stirring; . (the experiment can be done under air). The colour was changed to blue-violet light (The experiment was carried out at room temperature). Then $\mathrm{pH}$ was set between 6 and 7 ( $\mathrm{NaOH}$ was used). Here, based on the water (ordinary, 15 min-magnetized water, 30 min-magnetized water, 45 min-magnetized water, and 60 min-magnetized water) precipitate was obtained. Except for the ordinary water, the precipitate appeared, however, the colour was different from white to cream for 15, 30, 45, and 60 min magnetized water, respectively. Then they were transferred to the oven to be dried at 50 for $24 \mathrm{~h}$. The sample with ordinary water was dried. Finally, the precipitate was washed several times with an acidic solution (PH: 1) and distilled water to eliminate salt, and it was then dried under nitrogen atmosphere, and was transferred for the corresponding analyses.

Characterizations. XRD patterns were recorded by GNR Explorer advance using $1.541 \mathrm{~A}(\mathrm{Cu}-\mathrm{Ka})$. The FT-IR spectra were obtained by Avatar 370 spectrophotometer (in the range of 400-4000 cm-1). BET analysis was employed to measure the surface activity of the nanoparticles using capillary condensation of nitrogen at $77 \mathrm{~K}$ on a micrometric Belsorp-mini II. To estimate the mesoporosity and pore size distribution, the Barrett-Joyner-Halenda method (BJH) was applied. The microscopic images of the nanoparticles were detected by a FESEM microscope (TESCAN BRNO-Mira3 LMU) to study the morphology of the nanoparticles, was accompanied by EDX analysis. TEM images were taken by LEO 912AB through dispersing the samples into ethanol.

\section{Results And Discussion}

\subsection{Result}

Figure 3 illustrates the XRD pattern of $\mathrm{TiO}_{2}$ samples. Accordingly, no specific peak was observed when ordinary water was used. However, peaks appeared and crystallites formed by water magnetization. 
Waters magnetized for $15 \mathrm{~min}$ (sample 1) and $30 \mathrm{~min}$ (sample 2) were the best solvents due to the growth of peaks which indicates crystallinity. In the case of 30 min-magnetized water (Fig.3c), the XRD pattern exhibited diffraction peaks at $2 \theta=25.68,32.85,46.08,55.29,65.308$, and 75.16 . The index pattern of the samples is observable in Fig.3b and c. According to the index, it is an orthorhombic brookite phase, consistent with the standard XRD data for brookite $\mathrm{TiO}_{2}$ (JCPDS 76-1934). All diffraction peaks are sharp, illustrating a highly crystalline sample. Waters magnetized for $45 \mathrm{~min}$ and $60 \mathrm{~min}$ were not suitable as the peaks were reduced or vanished.

Crystalline size of the $\mathrm{TiO}_{2}$ nanoparticle obtained from the $30 \mathrm{~min}$-magnetized water was calculated by the Scherer equation (1) as $12 \mathrm{~nm}$ : see formula 1 in the supplementary files.

Figure 4 illustrates the FESEM images of the samples. For the ordinary water and those magnetized for 45, and $60 \mathrm{~min}$, no particular shape was observed. Even it was hard to detect a 3D structure. However, the diamond plate shape of brookite, as dominant structure, and spherical anatase shape related to $\mathrm{TiO}_{2}$ nanoparticle were observed in the case of the $30 \mathrm{~min}$-magnetized water.

EDX analysis of the $\mathrm{TiO}_{2}$ nanoparticle was carried out to analyze oxygen and titanium elements (Table 1). The result confirmed the purity of the obtained sample (Fig.5 and inserted). Carbon was common in the process of synthesis due to the use of high temperatures. However, as the temperature was not uniform, no impurity was detected in the composition.

The typical adsorption-desorption isotherms (BET method) and the pore distribution curve of samples are depicted in Fig. 6. Samples were degassed before BET measurement based on the IUPAC recommendation for $16 \mathrm{~h}$.

The micropores volume was calculated in the P/Po range of 0-0.990 to collect information about the type of porosity. BET surface activity and total pore volume (BJH method) were also considered. The hysteresis loop illustrates type- $\mathrm{V}$ indicating the formation of monolayer followed by multilayer and illustrates the presence of micropores. Moreover, the nanoparticle size was referenced to the mesoporous material; so the presence of mesoporous was proved [55]. The specific surface of the mesopores for both samples was calculated according to the differential molar adsorption work calculated from the adsorption-desorption isotherm (Table 2). The distribution of the adsorbent pore volume in terms of their diameters can be used to determine the maximum mesoporous diameter. All these data are listed in Table 2 .

Adsorption phenomenon depends on both the adsorbate and adsorbent. Langmuir is one of the methods to describe the distribution of metal ion such as titanium between two phases of liquid and solid. According to this method, monolayer adsorption on the surface holds a limited number of adsorption sites with identical strategies with no transmigration of adsorbate in the plane surface. After filling the site, adsorption won't occur implying that the surface has no more volume and is saturated. The data obtained from this analysis can be seen in Table 2. 
The surface state of the $\mathrm{TiO}_{2}$ nanoparticle was investigated by the FT-IR spectrum in the middle range of IR (400-4000 cm-1) (Fig. 7). The absorptions, between 3300-3400 $\mathrm{cm}^{-1}$ are related to the stretching vibrations of adsorbed water molecules. A different type of $\mathrm{H}_{2} \mathrm{O}$ molecule interacted with $\mathrm{TiO}_{2}$ nanoparticles, which resulted in the splitting the band into different component and containing their absorption into the formation of different types of $\mathrm{H}$-bonds on the surface.

There is also another peak at 1623 and $1626 \mathrm{~cm}^{-1}$, which is related to $(\delta(\mathrm{OH})$. Finally, the peaks at 520 $\mathrm{cm}^{-1}$ can be assigned to the band between $\mathrm{Ti}$ and $\mathrm{O}(\mathrm{Ti}-\mathrm{O})$ stretching in $\mathrm{TiO}_{6}$ octahedral with several types of desorption.

TEM imaging was carried out for further morphological investigations (Fig. 8). As can be seen, the brookite phase is the dominant phase (70-85\%). TEM image also illustrates diamond-shaped platelets of brookite and few spherical anatase particles (15-30\%). The brookite phase illustrates the basal faces matched to the [ [ $\left.\begin{array}{lll}3 & 0 & 1\end{array}\right]$ planes that are quasi-perpendicular to planes [ $\left[\begin{array}{lll}1 & 1 & 1\end{array}\right]$ and [ $\left[\begin{array}{lll}1 & 1 & 1\end{array}\right]$. There is also a plane of [0 20 l] as specified on the figure (Fig. 8, inserted). The mean size was obtained as $12 \mathrm{~nm}$, which well matches the size obtained by XRD analysis.

\subsection{Discussion}

Effect of the magnetic field on the water. The pure water is a polar liquid. A part of the water has a negative electric charge, while the other is positively charged. Overall, the total electric charge of the water molecule is negative. As the water molecule is a tiny magnet (Bipolar), its magnetic field can be affected by forcing the molecule to rotate in another direction by placing it in a positive and negative potential.

It has been proved that the positive electric charges make liquids softer [56] (not by reducing mineral compounds; but rather with less surface tension). The positive field makes all the obtained inorganic compounds hydrated through chopping liquid and solid compounds giving rise to crystals. Such imposed changes by the positive pole will influence the molecular structure and hence the crystallization of water molecules. Thus it will increase hydration, solubility, and ionization ending up in physical, structural, and behavior changes in the liquid. Ion mobility will be also increased remarkably in water molecules. This phenomenon will enhance the flow of solvent liquid, accumulation of bigger particles; the force obtained from the potential difference in processable solution is yield by $99.9 \%$ [57].

On the other hand, the negative pole ( $\mathrm{N}$ pole) differently affects the liquids. After the liquid passed this pole, particles are accumulated and hardness will increase the surface tension. This phenomenon can help in separation and precipitation. These changes in the electronic structure also influence the accumulation and crystallization of the water molecules and thus increase the hydration water, solubility and ionization. These variations will physically, structurally, and behaviorally alter the liquid. Naturally, liquid molecules are located in an absolute accidental structure, due to the small natural changes in their pure electric charge. As polar substances, they react anomalously to electric influence depending on the pure charge of extra force. As an example, a positive charge influences the physical properties of the 
liquid, so that the negative poles of molecules will be located in the nearest distance from the electric center (they absorb opposing charges and repel similar charges). After passing from the direct effect of extra electric force, molecules, with the highest pure-opposite charges, will be located in the nearest distance with the stimulus point, and inversely, the molecules with the highest identical pure charge will be situated in the farthest distance. The energized and amplified molecules, such as small magnets, become organized end to end, so that the energy of the pure charges becomes identical by the influence of extra magnet (Fig. 9). At the presence of a positive pole, electron rotation of atom is influenced giving rise to the electron orbital dense. In the case of water molecules, the hydrogen atoms are attracted to the oxygen atoms by the sharing electron. It reduces the bond length, so the bonding angles change from the triangular structure to a linear one (Fig. 10). In this mode, hydrogen atoms become more positive and tend to support the negatively charged oxygen atoms. It changes the pure negative charge of the ordinary water molecule to the pure positive charge of magnetized water, so it alters the magnet of water pure charge [58]. Moreover, as the angle becomes smaller, more water molecules, and therefore oxygen can settle in a unit of volume, which is proper for the synthesis of $\mathrm{TiO}_{2}$ with a more tense structure. Especially in the first step, when the aqueous complex of titanium is obtained (Eq.2) with a stable state.

Another effect of the magnetic device is related to the acidic and alkaline phenomena. By the increase of the magnetic device's effect, the acidic liquid tends to the alkaline and alkaline liquid goes toward the acidic mode. This device reduces the surface tension of water without any reduction in its chemical properties. It provides better solubility of oxygen in the water and softens the water. In water treatment, treated water is specified by the surface tension. The analysis illustrates that the hard water has a surface tension of $71 \mathrm{din} / \mathrm{cm}^{2}$ which declined to $62 \mathrm{din} / \mathrm{cm}^{2}$ for the case of magnetized water.

Water molecules are not designed individually and they attached by the hydrogen bonds. Whatever the molecules of water are less, their activity increases. The magnetic field decreases the number of monomolecules, thus enhancing their activity [59].

Proposed mechanism for the Formation of $\mathrm{TiO}_{2}$. It is a novel and unique method, applied for the first time to synthesis $\mathrm{TiO}_{2}$ nanoparticle. Indeed, synthesis of brookite $\mathrm{TiO}_{2}$ at room temperature is a challenging task, as it is the second stable phase among all the phases of $\mathrm{TiO}_{2}$ (Anatase>Brookite>Rutile) so it is hard to be formed without using high temperature $\mathrm{Ti}^{3+}$ is formed upon adding $\mathrm{HCl}$ to the solution of $\mathrm{TiCl}_{3}$, which then made an aqueous complex with the surrounding water (2) $[60,61]$ : see formula 2 in the supplementary files.

Adding $\mathrm{NaOH}$ turns the solution black from the light violet implying the formation of poly-cationic species due to a balance between $\mathrm{Ti}$ (III) and $\mathrm{Ti}$ (IV) [62,63]. Further addition of $\mathrm{NaOH}$ (PH9) will result in some blue precipitates. These precipitates are almost oxidized substance, $\mathrm{Ti}(\mathrm{OH})_{3+\mathrm{z}}$, in which $\mathrm{z}$ is related to the oxidation rate. However, these solids were not stable and they became white after drying $(50 \mathrm{C}$, $24 \mathrm{~h})$, as they turned into crystallized brookite. 
The effect of the magnetized water in the formation of $\mathrm{TiO}_{2}$. According to the previous work [64] and what we obtained in this project, upon using a magnetic field, the number of the hydrogen bond is increased due to the mentioned reason in the previous section; "the hydrogen atoms are attracted toward the oxygen atoms by the sharing electron. It reduces the bond length, so the bonding angles change from the triangular structure to the linear ones. In this mode, hydrogen atoms become more positive and tend to support the negatively charged oxygen atoms". This is the main effective parameter, which makes a big difference between ordinary and magnetized water.

Another important phenomenon is the concentration of $\mathrm{NaOH}$ during the synthesis procedure. The use of high-concentration $\mathrm{NaOH}$ weakens the net hydrogen bond; on the other hand, low-concentration $\mathrm{NaOH}$ does not allow for the precipitation. Here, the magnetic field can help. As it was mentioned, usage of the magnetic field increases the number of the hydrogen bond with no impact on the chemical reaction or stability of the bonds at high concentrations of $\mathrm{NaOH}$.

So based on the result, the magnetic field remarkably enhanced the stability and interaction force as compared to the ordinary water.

Moreover, the smaller the $\mathrm{O}-\mathrm{H}$ bond, the bigger the cluster size. Therefore, the pack structure of the water molecule got closer [65]. It is worth noting that the usage of the magnetic field reduced the selfdiffusion coefficient of the molecules, using a less step of solvent liquidity [64].

As the aim of this project was to use the magnetic field as an extra source to synthesis $\mathrm{TiO}_{2}$ nanoparticles, XRD and FESEM analysis were carried out under the same conditions. According to the result, the magnetic field interaction affected the growth of the nanoparticles, however, the use of the magnetic field for more than 30 min had a negative effect as it decomposed water. It is also important to mention that the attraction force on the particles is much higher when the magnetic field is used, which can influence the product morphology.

For a deeper investigation of the behavior of the system at the magnetic field, RDF analysis was carried out on the oxygen of $\mathrm{TiO}_{2}$ and the hydrogen atom of the water solvent. According to the analysis, there is a strong interaction between the oxygen atom of $\mathrm{TiO}_{2}$ and the hydrogen atom of water. It has been done for all the tests and the results were $2.342 \AA, 2.292 \AA, 2.21 \AA, 3.32 \AA$, and $3.41 \AA$ for ordinary water and those magnetized for $15,30,45$, and $60 \mathrm{~min}$, respectively. The result showed the strongest interaction between the mentioned atoms in the case 30-min magnetized water.

The mentioned results illustrate why magnetized water could influence the formation of $\mathrm{TiO}_{2}$ nanoparticle. The reasons, extracted from the "Effect of the magnetic field on the water" section provide information about the high formation of the precipitates. However, it should be mentioned that all the following reasons hold if they have a regular array in their molecular structure (See Fig. 9) and it has been obtained upon using the magnetic field. 
(I) "Positive field makes all the obtained inorganic compounds hydrated through chopping liquid and solid compounds resulting in crystal formation"

(II) "After the liquid passed the negative pole field, particles are accumulated and hardness will increase the surface tension. This phenomenon helps in separation and precipitation". The precipitate is $\mathrm{Ti}(\mathrm{OH})_{3+z}$ , which then progresses to $\mathrm{TiO}_{2}$.

\section{Conclusion}

$\mathrm{TiO}_{2}$ was synthesized by a method, which is absolutely compatible with the environment through magnetized water, obtained from the US-patent device for the first time. According to the result, 15 and 30 min magnetization resulted in the outcomes. However, 30 min magnetization could provide better conditions for obtaining $\mathrm{TiO}_{2}$ at room temperature. Indeed oxidation and precipitation resulted in the formation of $\mathrm{TiO}_{2}$. Thus, by controlling the condition through water magnetization, it was possible to obtain $\mathrm{TiO}_{2}$ with a desired crystal phase of brookite. Moreover, it was recognized it is possible to obtain ultra-small $\mathrm{TiO}_{2}$ nanoparticle under a soft condition.

The proposed method is highly environmentally friendly and economic as it optimizes two important parameters in the industries: a short procedure that does not require high temperatures and using magnetized water as green solvent.

\section{Declaration}

\section{Acknowledgements}

Funding for this research was provided by the Ministry of Education and Science of the Russian Federation (award no. 075-03-2020-223 (FSSF-2020-0017) ) and Ferdowsi University of Mashhad research Council

\section{Conflict of interest statement}

The authors declare that they have no known competing financial interests or personal relationships that could have appeared to influence the work reported in this paper

\section{References}

1. G. Zhou, Y. Cao, Y. Jin, C. Wang, Y. Wang, C. Hua, and S. Wu, J. Clean. Prod. 274, 122929 (2020).

2. N. Ahmadpour, M. H. Sayadi, S. Sobhani, and M. Hajiani, J. Clean. Prod. 268, 122023 (2020).

3. A. S. Abdulhameed, A. K. T. Mohammad, and A. H. Jawad, J. Clean. Prod. 232, 43 (2019).

4. M. A. de Bittencourt, A. M. Novack, J. A. Scherer Filho, L. P. Mazur, B. A. Marinho, A. da Silva, A. A. U. de Souza, and S. M. A. G. U. de Souza, J. Clean. Prod. 268, 122164 (2020). 
5. I. C. Kang, Q. Zhang, S. Yin, T. Sato, and F. Saito, Appl. Catal. B Environ. 80, 81 (2008).

6. X. Wang, M. Sun, M. Murugananthan, Y. Zhang, and L. Zhang, Appl. Catal. B Environ. 260, 118205 (2020).

7. J. Xu, N. Liu, D. Wu, Z. Gao, Y.-Y. Song, and P. Schmuki, ACS Nano 14, 337 (2020).

8. W.-T. Kim, K.-H. Na, J.-K. Lee, I. Jang, D.-S. Choi, and W.-Y. Choi, J. Nanosci. Nanotechnol. 19, 1743 (2018).

9. C. Pei, J.-H. Zhu, and F. Xing, J. Clean. Prod. 279, 123590 (2020).

10. R. Nasi, S. Esposito, F. Freyria, M. Armandi, T. Gadhi, S. Hernandez, P. Rivolo, N. Ditaranto, and B. Bonelli, Materials (Basel). 12, 937 (2019).

11. K. T. Lim and H. S. Hwang, Am. Chem. Soc. 20, 2466 (2003).

12. B. Stieberova, M. Zilka, M. Ticha, F. Freiberg, P. Caramazana-González, J. McKechnie, and E. Lester, J. Clean. Prod. 241, 118325 (2019).

13. Y. Shi, B. Sun, X. Wang, and D. Guo, Res. Appl. Mater. Sci. 1, (2019).

14. S. T. Rahmat, W. K. Tan, G. Kawamura, A. Matsuda, and Z. Lockman, J. Alloys Compd. 812, 152094 (2020).

15. B. N. Bhadra, J. Y. Song, N. Uddin, N. A. Khan, S. Kim, C. H. Choi, and S. H. Jhung, Appl. Catal. B Environ. 240, 215 (2019).

16. M. T. Le, H. L. Nguyen, A. Vu, V. C. Nguyen, and J. C. S. Wu, J. Chinese Chem. Soc. 66, 1713 (2019).

17. Q. Zhang and C. Li, Catal. Today (2019).

18. A. K. Singh, V. Chaudhary, A. K. Singh, and S. R. P. Sinha, Synth. Met. 256, 116155 (2019).

19. K. Kim, J. Park, H. Kim, G. Y. Jung, and M.-G. Kim, ACS Catal. 9, 9206 (2019).

20. (n.d.).

21. A. Vahl, S. Veziroglu, B. Henkel, T. Strunskus, O. Polonskyi, O. C. Aktas, and F. Faupel, Materials (Basel). 12, 2840 (2019).

22. R. Sharma, A. Sarkar, R. Jha, A. Kumar Sharma, and D. Sharma, Int. J. Appl. Ceram. Technol. ijac. 13439 (2019).

23. S. Das and A. Ghosh, J. Appl. Polym. Sci. 48757 (2019).

24. I. Heng, C. W. Lai, J. C. Juan, A. Numan, J. Iqbal, and E. Y. L. Teo, Ceram. Int. 45, 4990 (2019).

25. A. Mehrizad, M. A. Behnajady, P. Gharbani, and S. Sabbagh, J. Clean. Prod. 215, 1341 (2019).

26. J. Tian, Q. Shao, J. Zhao, D. Pan, M. Dong, C. Jia, T. Ding, T. Wu, and Z. Guo, J. Colloid Interface Sci. 541, 18 (2019).

27. A. G. R. Howe, R. Maunder, D. J. Morgan, and J. K. Edwards, Catalysts 9, 748 (2019).

28. D. B. Dwyer, D. J. Cooke, M. F. Hidalgo, B. Li, J. Stanton, F. Omenya, W. E. Bernier, and W. E. Jones, J. Fluor. Chem. 227, 109375 (2019).

29. Y. Absalan, M. A. Ryabov, and O. V. Kovalchukova, Mater. Sci. Eng. C 97, 813 (2019). 
30. Y. Absalan, E. A. Fortalnova, N. N. Lobanov, E. V Dobrokhotova, and O. V Kovalchukova, J. Organomet. Chem. 859, 80 (2018).

31. Y. Absalan, I. G. Bratchikova, and O. V. Kovalchukova, J. Mol. Liq. 268, 882 (2018).

32. Y. Absalan, I. Bratchikova, and O. V.Kovalchukova, Environ. Nanotechnology, Monit. Manag. J. 8, 244 (2017).

33. Y. Absalan, I. Bratchikova, Labanov, and O. V.Kovalchukova, J Mater Sci Mater Electron 28, 18220 (2017).

34. Y. Absalan, O. V.Avramenko, and and O. V. Kovalchukova, Butlerov Commun. 47, 49 (2016).

35. Z. Shayegan, C.-S. Lee, and F. Haghighat, Chem. Eng. J. 334, 2408 (2018).

36. A. Hashemizadeh, M. J. Amiri, B. Aminshahidi, and M. Gholizadeh, CORROSION 1 (2016).

37. Z. Eshaghi and M. Gholizadeh, Talanta 64, 558 (2004).

38. G. H. Rounaghi, M. Gholizadeh, F. Moosavi, I. Razavipanah, H. Azizi-toupkanloo, and M. R. Salavati, RSC Adv. 6, 9096 (2016).

39. M. Bakherad, F. Moosavi, R. Doosti, A. Keivanloo, and M. Gholizadeh, New J. Chem. 42, 4559 (2018).

40. M. Bakherad, R. Doosti, A. Keivanloo, and M. Gholizadeh, J. Iran. Chem. Soc. 14, 2591 (2017).

41. M. Bakherad, Z. Moosavi-Tekyeh, A. Keivanloo, M. Gholizadeh, and Z. Toozandejani, Res. Chem. Intermed. 44, 373 (2017).

42. M. Bakherad, R. Doosti, A. Keivanloo, M. Gholizadeh, and A. H. Amin, Lett. Org. Chem. 14, 510 (2017).

43. A. N. Pour, J. Karimi, and M. Gholizadeh, J. Iran. Chem. Soc. 14, 1477 (2017).

44. H. Rashidi, A. Ahmadpour, M. Gholizadeh, F. F. Bamoharram, and F. Moosavi, Adv. Powder Technol. 29, 349 (2018).

45. P. M. E. Parthiban, P. M. R. M. E, and S. George, Int. J. Eng. Res. Technol. ISSN 4, 65 (2016).

46. H. Afshin, M. Gholizadeh, and N. Khorshidi, Trans. A Civ. Eng. 17, 74 (2010).

47. S. Ghorbani and M. Gholizadeh, Materials (Basel). 11, 1 (2018).

48. M. Gholizadeh and H. Arabshahi, J. Eng. Technol. Res. 3, 77 (2011).

49. A. Gilani, H. Kermanshahi, A. Golian, and M. Gholizadeh, Iran. J. Appl. Anim. Sci. 3, 687 (2013).

50. M. Gholizadeh, H. Arabshahi, M. R. Saeidi, and B. Mahdavi, Middle-East J. Cient. Res. 3, 140 (2008).

51. E. Esmaeilnezhad, H. J. Choi, M. Schaffie, M. Gholizadeh, and M. Ranjbar, J. Clean. Prod. 171, 45 (2018).

52. A. Gilani, H. Kermanshahi, and M. Gholizadeh, J. Arid. Agric. 3, 23 (2017).

53. M. Gholizadeh, US 10507 450B2 (2019).

54. E. Esmaeilnezhad, H. Jin, M. Schaf, and M. Gholizadeh, J. Clean. Prod. J. 161, 908 (2017).

55. S. Mobini, F. Meshkani, and M. Rezaei, Process Saf. Environ. Prot. 107, 181 (2017).

56. B.S.Joshi and V.N.Kamat, Tetrahedron Lett. 7, 5767 (1966).

57. M. R. Powell, Skept. Inq. 22, (1998). 
58. J. Zheng, P. Xu, M. Gu, J. Xiao, N. D. Browning, P. Yan, C. Wang, and J. G. Zhang, Chem. Mater. 27, 1381 (2015).

59. (n.d.).

60. E. Sum and M. Skyllas-Kazacos, J. Power Sources 15, 179 (1985).

61. D. J. Cookson, T. D. Smith, and J. R. Pilbrow, Cancer Res. 23, 833 (1963).

62. K.W.Stephens and Chris Orvig, Inorganica Chim. Acta 273, 47 (1998).

63. Aa. N. F. Pecsok, B Y Robert L, Inorg. Chem. 1, 155 (1968).

64. H. Rashidi, A. Ahmadpour, M. Gholizadeh, F. F. Bamoharram, and F. Moosavi, Adv. Powder Technol. 29, 349 (2018).

65. H. Hosoda, H. Mori, N. Sogoshi, A. Nagasawa, and S. Nakabayashi, J. Phys. Chem. A 108, 1461 (2004).

\section{Tables}

Table 1 not available with this version.

Table 2. Physical-chemical characterization of $\mathrm{TiO}_{2}$ nanoparticle (30min-magnetized water)

\begin{tabular}{|c|c|}
\hline \multicolumn{2}{|l|}{ Experiment's properties } \\
\hline Sample weight [g] & 0,0833 \\
\hline Standard volume $\left[\mathrm{cm}^{3}\right]$ & 9,779 \\
\hline Dead volume $\left[\mathrm{cm}^{3}\right]$ & 12,19 \\
\hline Equilibrium time [sec] & 0 \\
\hline Adsorptive & $\mathrm{N} 2$ \\
\hline Apparatus temperature $[\mathrm{C}]$ & 0 \\
\hline Adsorption temperature $[\mathrm{K}]$ & 77.000 \\
\hline \multicolumn{2}{|l|}{ BET } \\
\hline$V_{m}\left[\mathrm{~cm}^{3}(\mathrm{STP}) \mathrm{g}^{-1}\right]$ & 31,88 \\
\hline $\mathrm{a}_{\mathrm{s}, \mathrm{BET}}\left[\mathrm{m}^{2} \mathrm{~g}^{-1}\right]$ & 138,76 \\
\hline$C$ & 37,422 \\
\hline Total pore volume $\left(p / p_{0}=0.990\right)\left[\mathrm{cm}^{3} \mathrm{~g}^{-1}\right]$ & 0,1616 \\
\hline Mean pore diameter $[\mathrm{nm}]$ & 4,6577 \\
\hline \multicolumn{2}{|l|}{ Langmuir plot } \\
\hline $\mathrm{V}_{\mathrm{m}}\left[\mathrm{cm}^{3}(\mathrm{STP}) \mathrm{g}^{-1}\right]$ & 32,82 \\
\hline $\mathrm{a}_{\mathrm{s}, \text { Lang }}\left[\mathrm{m}^{2} \mathrm{~g}^{-1}\right]$ & 142,85 \\
\hline B & 0,6821 \\
\hline \multicolumn{2}{|l|}{ t- plot } \\
\hline$a_{1}\left[m^{2} g^{-1}\right]$ & 144,47 \\
\hline $\mathrm{V}_{1}\left[\mathrm{~cm}^{3} \mathrm{~g}^{-1}\right]$ & 0 \\
\hline $\mathrm{a}_{2}\left[\mathrm{~m}^{2} \mathrm{~g}^{-1}\right]$ & 17,869 \\
\hline $\mathrm{V}_{2}\left[\mathrm{~cm}^{3} \mathrm{~g}^{-1}\right]$ & 1,9945 \\
\hline $2 \mathrm{t}[\mathrm{nm}]$ & 144,47 \\
\hline \multicolumn{2}{|l|}{ BJH plot } \\
\hline $\mathrm{V}_{\mathrm{p}}\left[\mathrm{cm}^{3} \mathrm{~g}^{-1}\right]$ & 0,155 \\
\hline$r_{p, \text { peak }}($ Area $)[\mathrm{nm}]$ & 1,22 \\
\hline$a_{p}\left[m^{2} g^{-1}\right]$ & 131,79 \\
\hline
\end{tabular}


Figures

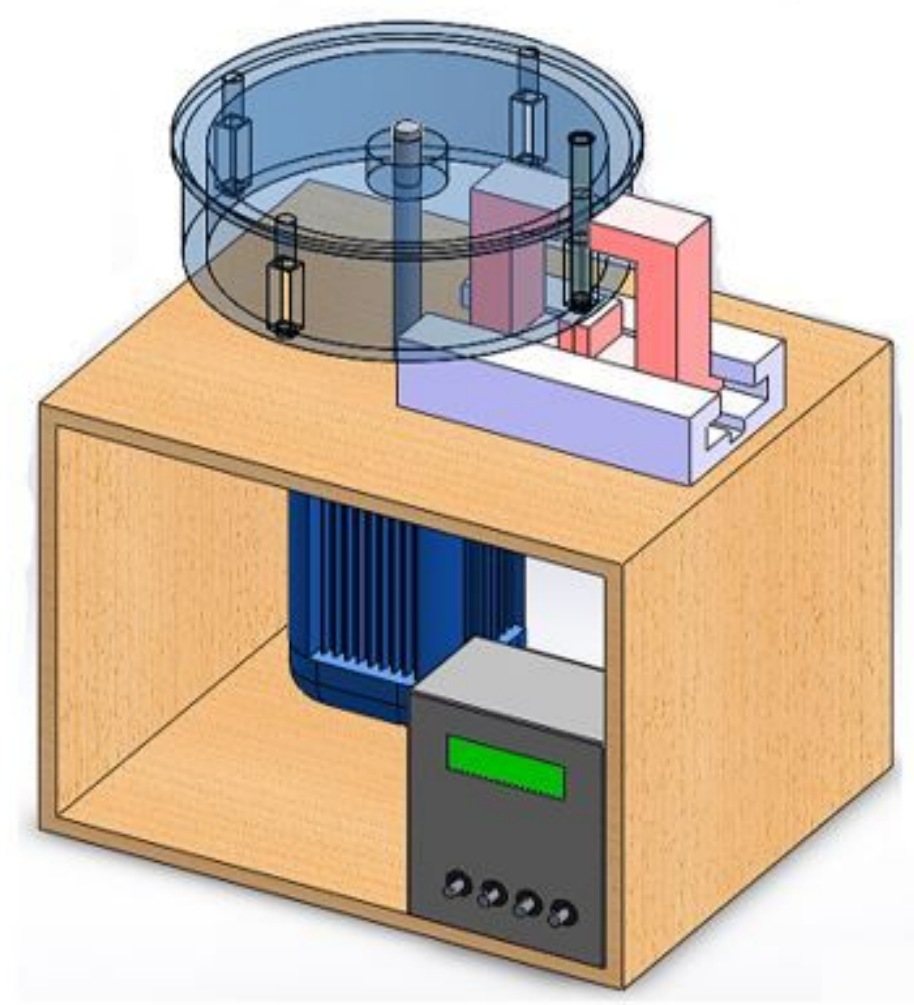

Figure 1

Micro Magnetic Device

(a)

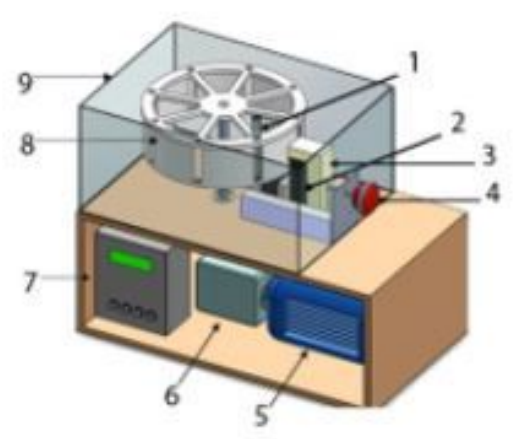

(b)

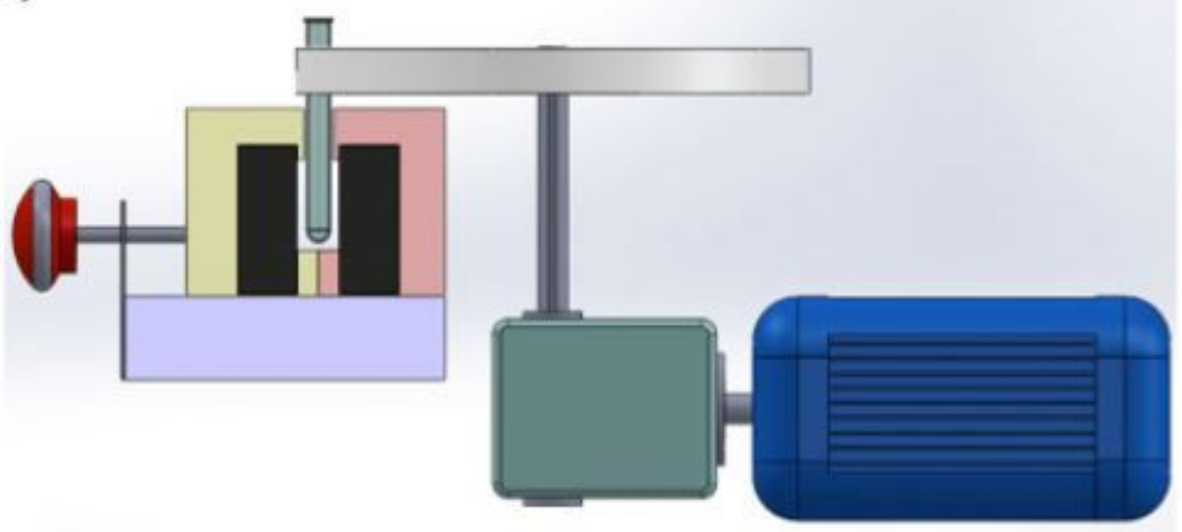

Figure 2 
(a) The general scheme of the micro magnetizing fluids apparatus, (b) Interior schematic of the microdevice

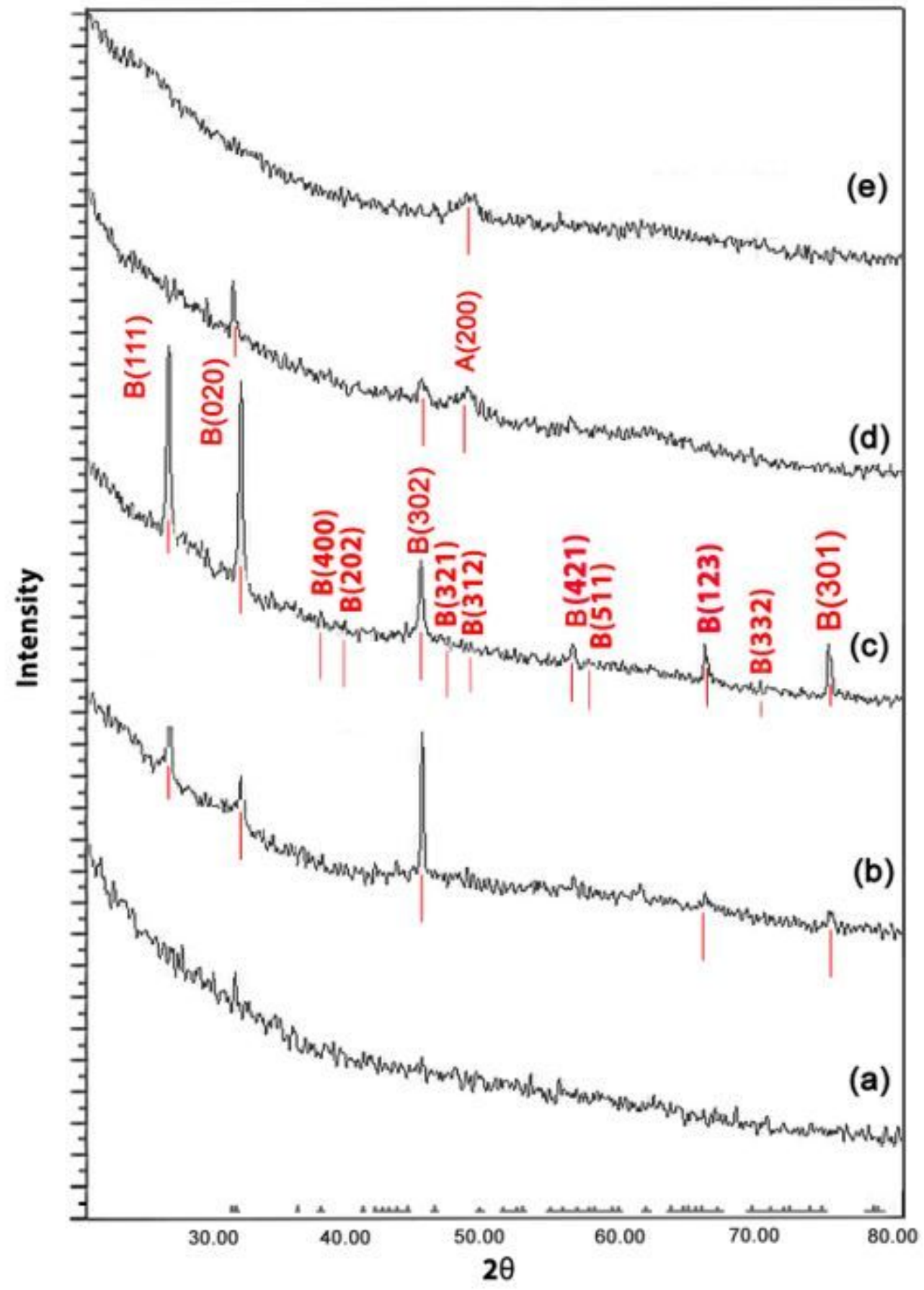

\section{Figure 3}

XRD pattern; (a) ordinary water, (b) magnetized water (15min), (c) magnetized water (30 min), (d) magnetized water (45 min), (e) magnetized water (60 min) 

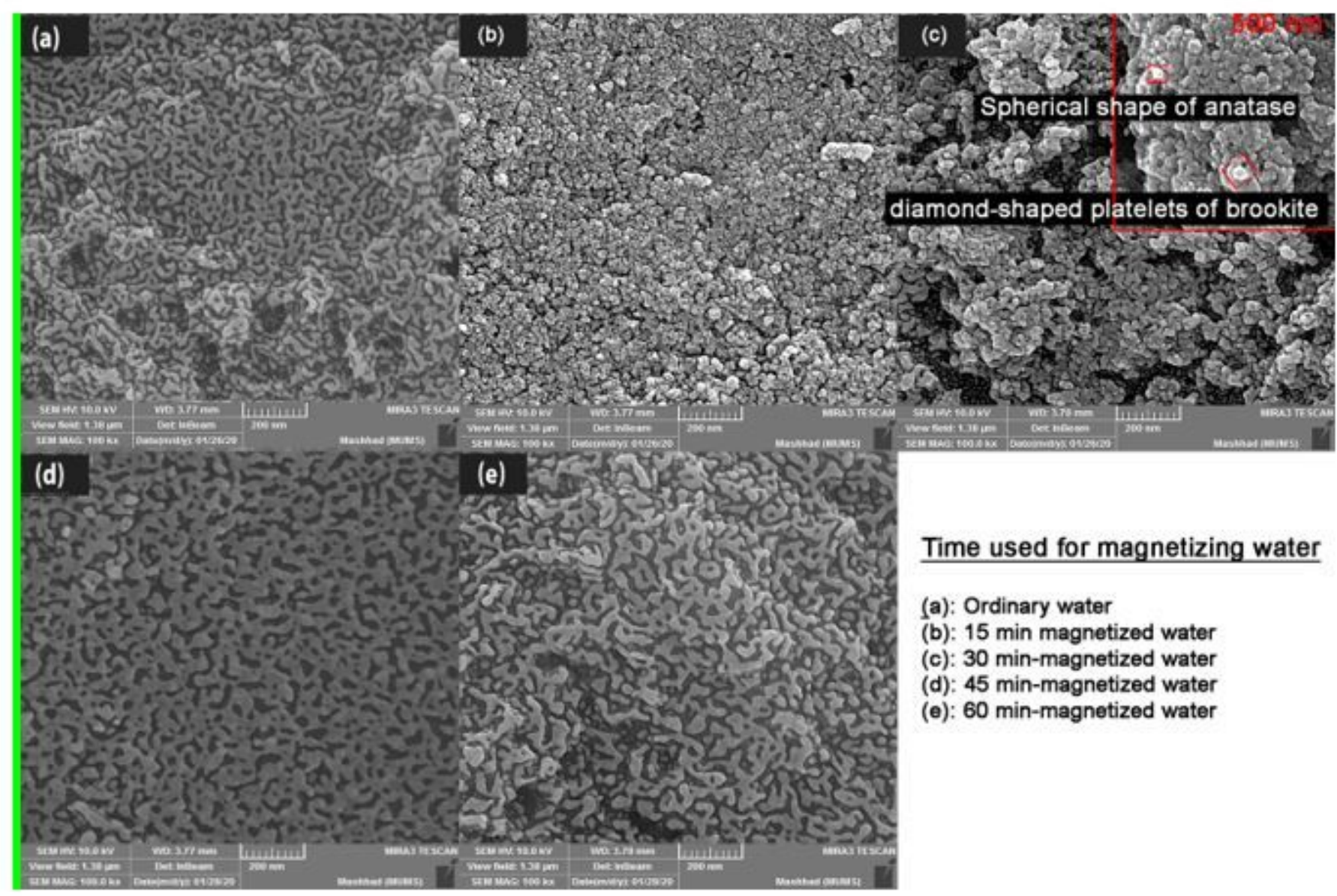

\section{Time used for magnetizing water}

(a): Ordinary water

(b): 15 min magnetized water

(c): 30 min-magnetized water

(d): 45 min-magnetized water

(e): 60 min-magnetized water

\section{Figure 4}

FESEM image of the samples 


\begin{tabular}{lll}
\hline Sample & O (weight \%) & Ti (weight \%) \\
\hline $\mathrm{TiO}_{2}$ (used 30 min magnetized water) & 49.87 & 50.13 \\
\hline
\end{tabular}

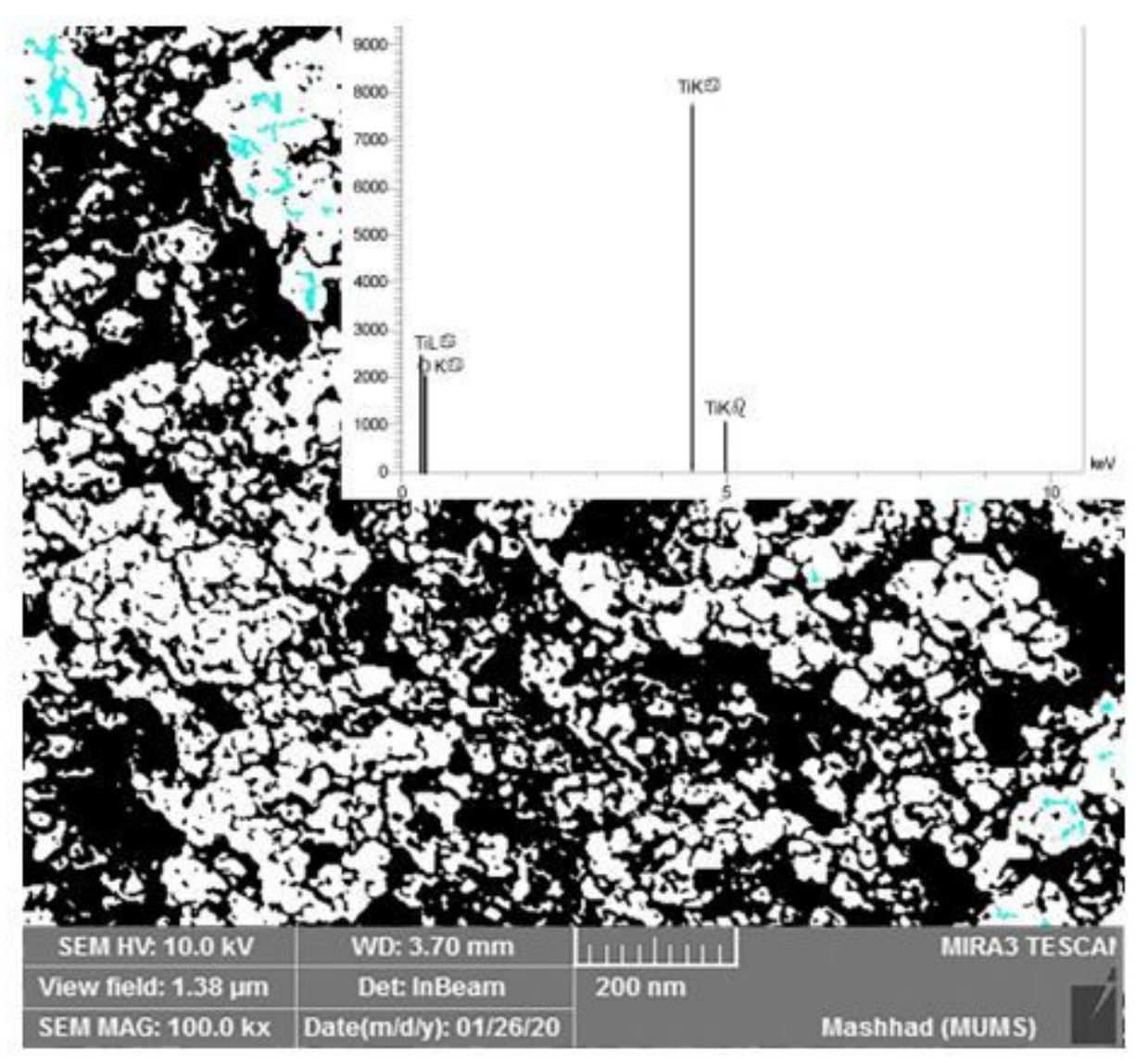

Figure 5

EDX pattern of TiO2 nanoparticle 

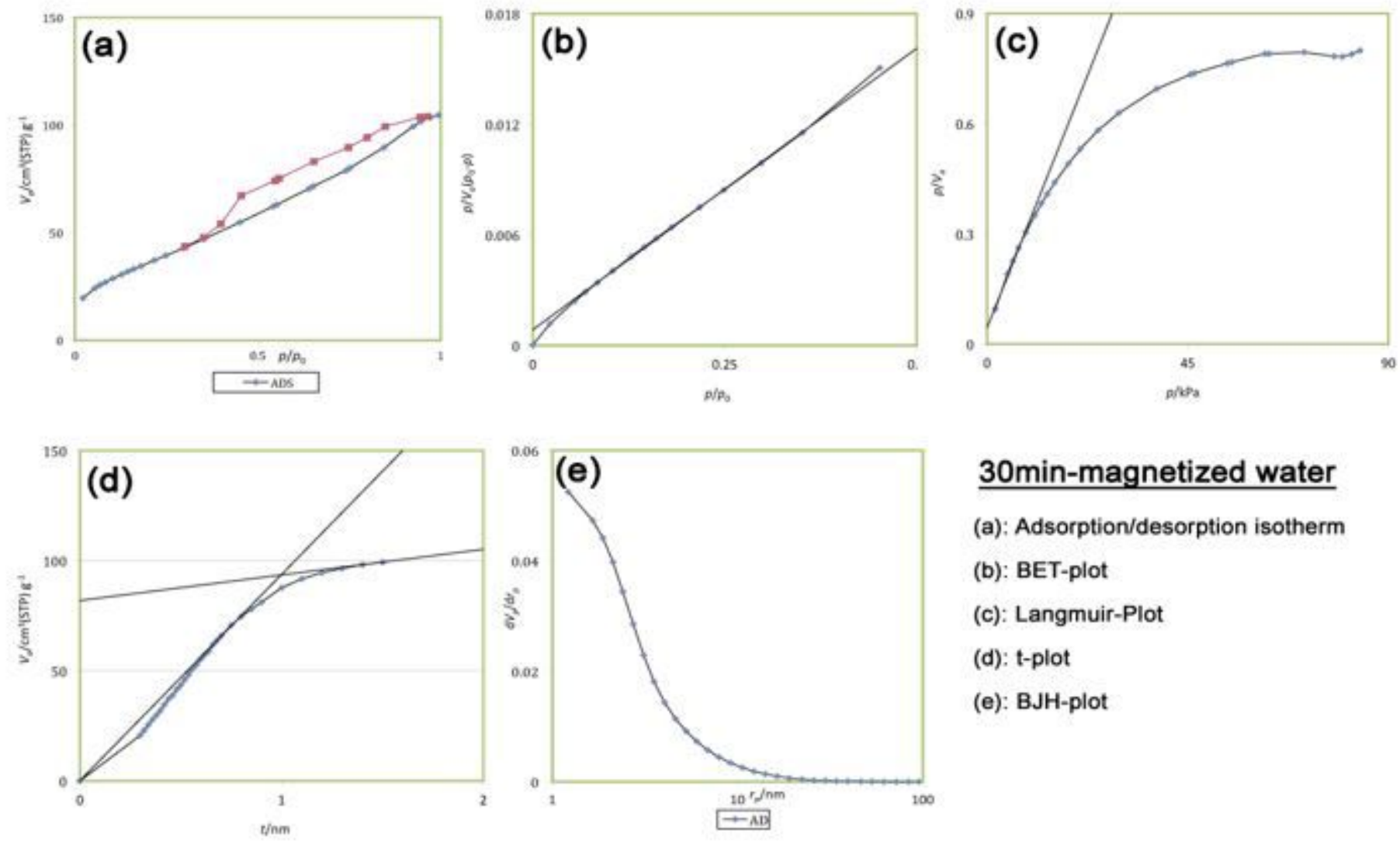

\section{0min-magnetized water}
(a): Adsorption/desorption isotherm
(b): BET-plot
(c): Langmuir-Plot
(d): t-plot
(e): BJH-plot

\section{Figure 6}

Physical-chemical analysis of $\mathrm{TiO} 2$ nanoparticle

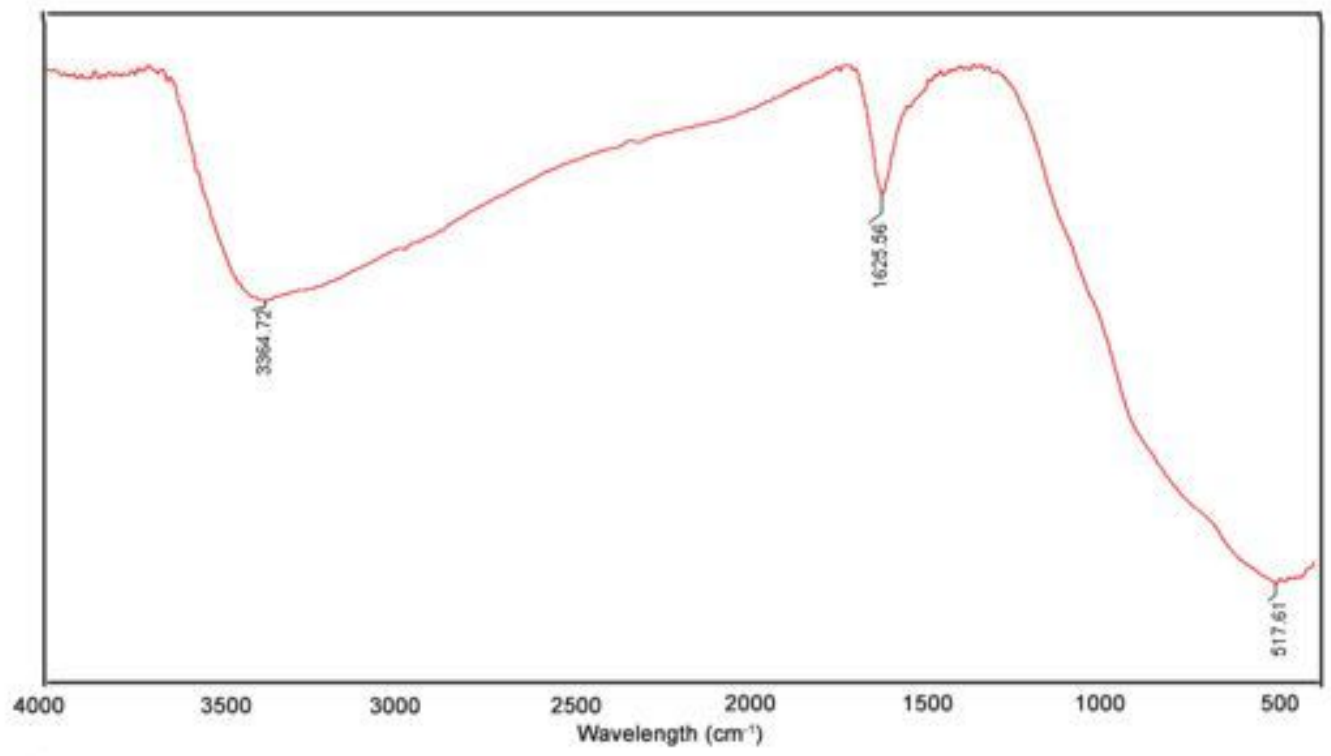

\section{Figure 7}

FTIR spectroscopy of TiO2 nanoparticle 


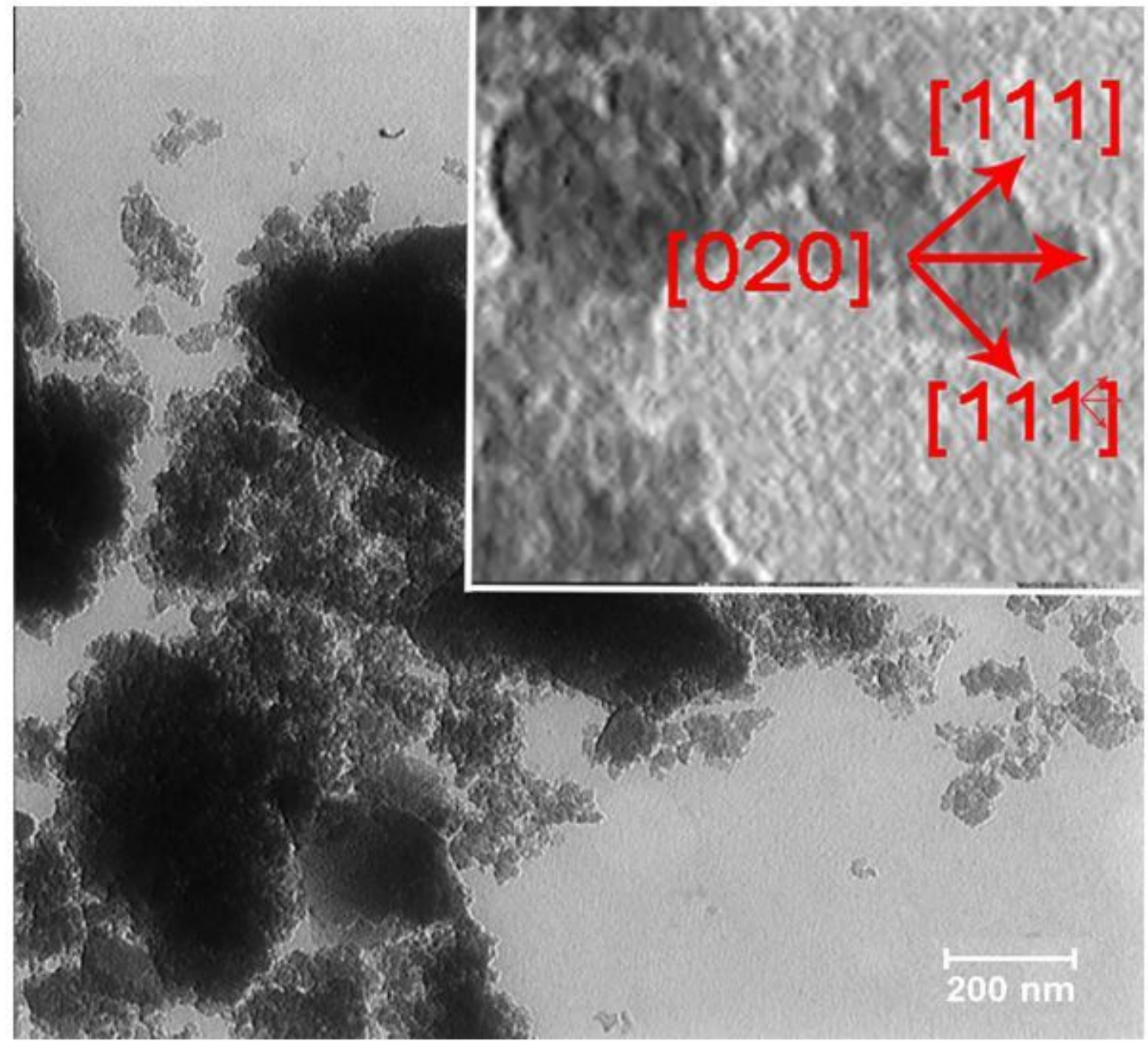

Figure 8

The TEM image of TiO2 nanoparticle

(a)

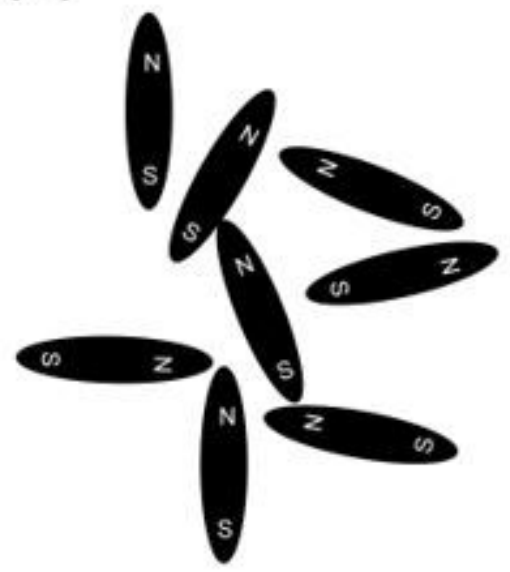

(b)

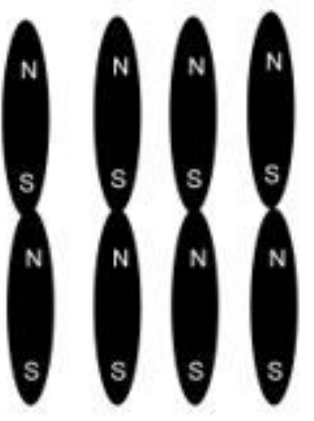




\section{Figure 9}

The influence of magnetic field on the molecular structure; (a) Before passing the magnetic field, (b) After passing the magnetic field water

(a)

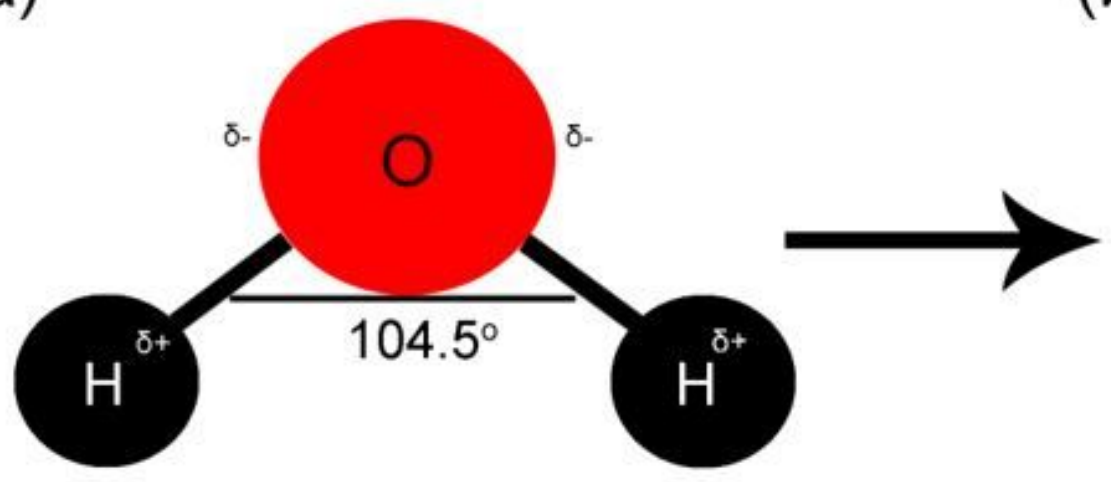

(b)

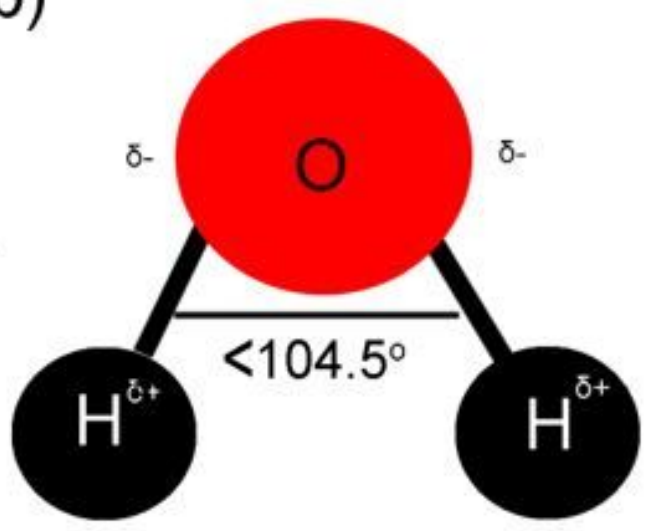

Figure 10

The molecular structure of water; (a) before magnetizing, (b) after magnetizing

\section{Supplementary Files}

This is a list of supplementary files associated with this preprint. Click to download.

- formulas.docx 